\title{
Genetic Architecture and QTL Selection Response For Kernza Perennial Grain Domestication Traits
}

\section{Jared Crain}

Kansas State University

\section{Steve Larson}

USDA-ARS

Kevin Dorn

USDA-ARS

Lee DeHaan

The Land Institute

Jesse Poland ( $\square$ jesse.poland@kaust.edu.sa )

King Abdullah University of Science and Technology https://orcid.org/0000-0002-7856-1399

\section{Research Article}

Keywords: Domestication, genome-wide association study, intermediate wheatgrass, Kernza, perennial grain, Thinopyrum intermedium

Posted Date: October 6th, 2021

DOl: https://doi.org/10.21203/rs.3.rs-933049/v1

License: (c) (i) This work is licensed under a Creative Commons Attribution 4.0 International License.

Read Full License 
1 Genetic architecture and QTL selection response for Kernza perennial grain domestication traits

3 Jared Crain ${ }^{1}$, Steve Larson ${ }^{2}$, Kevin Dorn ${ }^{3}$, Lee DeHaan ${ }^{4}$, Jesse Poland ${ }^{1,5}$

$4 \quad{ }^{1}$ Department of Plant Pathology, Kansas State University, 4024 Throckmorton Plant Sciences

5 Center, Manhattan KS, USA 66506

$6 \quad{ }^{2}$ USDA-ARS, Forage and Range Research, Utah State University, Logan, UT USA 84322

$7 \quad{ }^{3}$ USDA-ARS, Soil Management and Sugarbeet Research, Fort Collins, CO 80526, USA

$8 \quad{ }^{4}$ The Land Institute, 2440 E. Water Well Rd, Salina KS, USA 67401

$9{ }^{5}$ Center for Desert Agriculture, King Abdullah University of Science and Technology, Thuwal

10 Saudi Arabia

11

\section{Author Correspondence:}

13 Jesse Poland

14 email: jesse.poland@kaust.edu.sa; jpoland@ksu.edu

15

Author ORCID list:

17 Jared Crain (0000-0001-9484-8325)

18 Steve Larson (0000-0003-2742-2134)

19 Kevin Dorn (0000-0003-2722-6221)

20 Lee DeHaan (0000-0002-6368-5241)

21 Jesse Poland (0000-0002-7856-1399)

22

23

24 


\section{KEY MESSAGE}

26 Analysis revealed that the genetic architecture of an intermediate wheatgrass population was

27 highly polygenic for both domestication and agronomic traits supporting the use of genomic

28 selection for new crop domestication.

\section{ABSTRACT}

30 Perennial grains have the potential to provide food for humans as well as decrease the negative

31 impacts of annual agriculture. Intermediate wheatgrass (IWG, Thinopyrum intermedium,

32 Kernza $\left.{ }^{\circledR}\right)$ is a promising perennial grain candidate that The Land Institute has been breeding

33 since 2001. We evaluated four consecutive breeding cycles of IWG from 2016-2020 with each

34 cycle containing approximately 1100 unique genets. Using genotyping-by-sequencing markers,

35 quantitative trait loci (QTL) were mapped for 34 different traits using genome-wide association

36 analysis Combining data across cycles and years, we found 93 marker-trait associations (MTA)

37 for 16 different traits, with each association explaining 0.8-5.2\% of the observed phenotypic

38 variance. Across the four cycles, only three QTL showed an $F_{S T}$ differentiation $>0.15$ with two

39 corresponding to a decrease in floret shattering. Additionally, one marker associated with brittle

40 rachis was $216 \mathrm{bp}$ from an ortholog of the $b t r 2$ gene. Power analysis and quantitative genetic

41 theory was used to estimate the effective number of QTL, which ranged from a minimum of 33

42 up to 558 QTL for individual traits. This study suggests that key agronomic and domestication

43 traits are under polygenic control, and that molecular methods like genomic selection are needed

44 to accelerate domestication and improvement of this new crop. 


\section{KEY WORDS}

48 Domestication, genome-wide association study, intermediate wheatgrass, Kernza, perennial

49 grain, Thinopyrum intermedium

\section{ABBREVIATIONS}

51 BLUP, best linear unbiased predictor; FDR, false discovery rate; $F_{S T}$, fixation index; FSU, floret 52 site utilization; GBS, genotyping-by-sequencing; GRM, genomic relationship matrix; GS,

53 genomic selection; GWAS, genome wide association study; IWG, intermediate wheatgrass; LD,

54 linkage disequilibrium; LOD, logarithm of the odds; MTA, marker-trait association; PVE,

55 percent variance explained; QTL, quantitative trait loci; SNP, single nucleotide polymorphism;

56 TLI, The Land Institute

57

58 


\section{INTRODUCTION}

60 Perennial grain crops have the potential to revolutionize agriculture. In contrast to their annual

61 counterparts that require regular tillage and anthropogenic disturbances (Crews et al. 2018),

62 perennials could provide a host of ecosystem services (Glover et al. 2010; Crews et al. 2018).

63 Documented ecosystem services by perennial crops include reduced nitrate leaching (Culman et

64 al. 2013; Jungers et al. 2019), more complex soil communities (Culman et al. 2010), greater

65 ability to store and retain carbon (Sprunger et al. 2018), and increased nutrient cycling (Pugliese

66 et al. 2019). Although there are currently no large scale perennial grain crops, the development

67 and utilization of such crops could transform both the sustainability and economic foundations of

68 agriculture (Crews et al. 2018).

69 Intermediate wheatgrass (IWG, Thinopyrum intermedium (Host) Barkworth \& D.R. Dewey,

70 trade name Kernza) is the closest perennial relative of wheat and has a similar allohexaploid

71 genome $(2 n=6 x=42)$. Based on comparisons of nearly 100 species of perennial grasses, IWG

72 was first identified for domestication in the 1980's by work at the Rodale Institute (Kutztown,

73 Pennsylvania, USA) because of its relatively large seed size, promising yield, and palatability

74 (Wagoner 1990a, b). In addition to more favorable agronomic traits, the grain has a soft

75 endosperm comparable to soft wheat (Triticum aestivum) (Bajgain et al. 2020b), with quality

76 evaluations showing IWG has higher levels of amino acids, protein, and bran percentage than

77 wheat (Becker et al. 1991). Even though IWG has higher grain yield than many perennials, it is

78 estimated to only be 10-20\% of the yield of annual wheat (DeHaan et al. 2014; DeHaan and

79 Ismail 2017), necessitating sustained breeding efforts to increase the yield of this potential grain

80 crop. Additionally, several other agronomic and domestication traits such as reduced shattering,

81 increased seed size, and improved threshability are needed to make IWG a mainstream crop.

82 Uninterrupted breeding efforts to improve IWG have been conducted at The Land Institute

83 (TLI), Salina, Kansas, USA, since 2001 (DeHaan et al. 2018), with new breeding programs being

84 initiated in Minnesota, USA (2011), Manitoba, Canada (2011), Utah, USA (2019), and Uppsala,

85 Sweden (2019) (Cattani 2016; Zhang et al. 2016; Bajgain et al. 2020b). While the initial cycles

86 of selection relied on recurrent phenotypic selection (Zhang et al. 2016; DeHaan et al. 2018),

87 advances in low cost, high-throughput DNA sequencing has permitted IWG breeding to harness

88 the power of genomic selection (GS) (Zhang et al. 2016; Bajgain et al. 2020a; Crain et al. 2020a, 
2021b, a). Within TLI's breeding program, GS has reduced the breeding cycle from three years

90 to one year per cycle (DeHaan et al. 2018) and simultaneously maintained an estimated 8\% year

$91{ }^{1}$ increase in spike yield (Crain et al. 2021a). Furthermore, decreased sequencing cost has

92 resulted in a wealth of genomic information for crop improvement including genetic maps

93 (Kantarski et al. 2016), a draft genome sequence (https://phytozome-

94 next.jgi.doe.gov/info/Tintermedium_v2_1). These genomics resources have enabled genome-

95 wide association studies (GWAS) for agronomic traits including seed size (Zhang et al. 2017;

96 Larson et al. 2019), flowering time (Altendorf et al. 2021b), and grain yield components (Bajgain

97 et al. 2019; Larson et al. 2019) that can be used to better understand and guide IWG breeding.

98 Since initiating GS in 2017, TLI has completed four cycles of selection for reducing seed

99 shattering, enhancing threshability to produce naked seed (free-threshing trait), increasing seed

100 mass, and developing higher yield per spike. Even though selections have been primarily based

101 on GS models for these few primary traits, up to 34 traits have been measured which allow for a

102 holistic assessment of the breeding program. The estimated genetic gains have generally been

103 favorable and at a more rapid rate than phenotypic selection alone, yet there has been some

104 evidence of unanticipated results. Within the breeding program, increasing spike yield has been

105 associated with increased seeds per spike, number of florets per spike, and florets per spikelet,

106 yet the floret site utilization (FSU, referred to as percent seed set in Crain et al., 2021a)

107 decreased, suggesting less efficient use of resources. While FSU has not been a direct target of

108 selection in the TLI program, Altendorf et al. (2021a) have found that FSU was the primary

109 driver of yield for spaced plants grown on $1 \mathrm{~m}$ centers (e.g. one-meter spacing between plants).

110 Within annual wheat, increasing the number of seeds per spikelet (Würschum et al. 2018) or

111 spike fertility, percent of grain weight to total spike weight, has been shown to increase yield

112 (Alonso et al. 2018), yet Philipp et al. (2018) reported that there appears to be little evidence that

113 the number of spikelets per spike has been improved in elite varieties from landraces or wild

114 germplasm. Wheat and barley display indeterminant numbers of fertile florets per spikelet or

115 spikelets per spike, respectively, but are otherwise determinate for these traits, illustrating

116 different ways of increasing the number of seed per spike (Zhong et al. 2021). Although IWG is

117 indeterminate for the number of fertile florets per spikelet and spikelets per spike, a key element

118 that should be considered is the difference between annual and perennial life cycle, specifically if 
119 a high yielding perennial grain crop is viable. Research has shown that perennials devote more

120 resources below ground than do their annual counterparts, and that this allocation is a precursor

121 to switching between perennial and annual life cycles (Lindberg et al. 2020). Additionally,

122 selecting for higher seed yield may induce concessions from below ground resources and plant

123 longevity (Vico et al. 2016).

124 While there are some arguments against perennial grains due to the ecological and physiological

125 limitation of perennial plants (Smaje 2015), current work suggest that favorable gains can be

126 made through artificial selection (DeHaan et al. 2014; Zhang et al. 2016; Crain et al. 2021a). As

127 breeding programs mature, they should assess whether the realized gains in perennial crops are

128 matching the target gains for both agronomic yield and increased ecosystem services. Given the

129 rapid cycling nature of the TLI IWG breeding program and the results from the first few cycles

130 of GS (Crain et al. 2021a), our objectives are to 1) conduct a GWAS for observed traits to

131 identify associated loci for key agronomic traits, 2) determine the genetic architecture of the

132 observed traits, 3) assess allele frequency changes across the four cycles of selection for

133 significant marker-trait associations, and 4) evaluate the potential selection opportunities to drive

134 genetic gains for desirable physiological and agronomic outcomes such as high grain yield and

135 high FSU. 
Plant Material

138 All plant material used in this study came from the TLI breeding program, Cycles 6 to 9, with TLI-Cycle 6 being extensively described in DeHaan et al. (2018) and TLI-Cycles 7 to 9 detailed in Crain et al. (2021a, b). Briefly, TLI-cycle 6 formed the initial training population for GS and

141 consisted of 3,658 space planted genets that were evaluated in 2016 and 2017 at Salina, KS

142 (Crain et al. 2021b). As outcrossed IWG plants are all unique and heterozygous (excluding 143 clones or ramets), the term "genet" herein refers to a genetically unique individual which is 144 typically a single plant but possibly cloned ramets, while genotype herein refers to the DNA 145 sequence of a particular genet (Zhang et al. 2016). Phenotypic data alone was used to select TLI146 Cycle 6 genets that were randomly intermated to form TLI-Cycle 7. Genomic selection was used 147 to identify 118 TLI-Cycle 7 genets, out of 4,183 genotyped, to intermate to form TLI-Cycle 8 148 seed. Another 1,216 TLI-Cycle 7 genets were selected for field evaluations to train future GS 149 models and divided randomly between an irrigated and non-irrigated site. Genets were space 150 planted on $0.91 \mathrm{~m}$ centers in the fall of 2017 with phenotypic evaluations in 2018, 2019, and

151 2020. TLI-Cycle 8 and 9 were formed in a same manner with around 100 selected genets 152 intermated to form each subsequent cycle out of nearly 3,500 genotyped genets. Planting was 153 similar to TLI-Cycle 7, where individual genets were divided between irrigated and non-irrigated 154 sites and planted on $0.91 \mathrm{~m}$ centers. TLI-Cycle 8 training population consisted of 1,092 genets 155 planted in the field in the fall of 2018 and evaluated during 2019 and 2020. The TLI-Cycle 9 156 training population was comprised of 1,004 genets, planted in the fall of 2019 with first year 157 phenotypic observations in 2020. Across all cycles, there was no replication of genets, thus each 158 genet was evaluated as a unique single plant.

\section{Phenotypic Assessment}

160 Each year phenotypic traits were measured to evaluate genet performance, with a total 34 unique 161 traits (Crain et al. 2021a). Within the breeding program the most important traits which are key

162 selection targets include shattering, percent free-threshing seed, seed mass, and spike yield.

163 Shattering was rated on a scale of 0 to 5 , where 0 indicated no shattering and 5 indicated more 164 than 12 florets shattering per evaluated spike (DeHaan et al., 2018). From 2016 to 2018, 165 shattering was considered a single trait; however, work by Altendorf (2020) indicated that floret 
166

167

168

169

170

171

172

173

174

175

176

177

178

179

180

181

182

183

184

185

186

187

188

189

190

191

192

193

194

195

and brittle rachis shattering should be scored separately, so beginning in 2019 brittle rachis was scored as a separate trait in the IWG population. In addition, many other secondary traits including seeds spike ${ }^{-1}$, spikelets spike ${ }^{-1}$, florets spike ${ }^{-1}$, and FSU were evaluated. While most traits were assessed consistently across years and cycles, it should be noted that TLI-Cycle 6 had significant missing data due to flooding, and reduced data collection in 2020 reflected limited labor due to the COVID-19 pandemic. A subset of 1,470 TLI-Cycle 6 genets were selected to make approximately equal representation of genet number between cycles and follows previous work by Crain et al. (2021a).

A linear mixed model, Eqn. 1, was used to calculate trait best linear unbiased predictors (BLUPs) for each genet using ASREML version 4.1 (Gilmour et al. 2015).

$$
\boldsymbol{y}=\boldsymbol{X} \boldsymbol{b}+\boldsymbol{Z u}+\boldsymbol{e} \quad \text { Equation } 1
$$

In Eqn. 1, $\boldsymbol{y}$ is a vector of phenotypic observations, fixed and random effects are given by vector $\boldsymbol{b}$ and $\boldsymbol{u}$ respectively, and $\boldsymbol{e}$ is a vector of residuals. The incidence matrices $\boldsymbol{X}$ and $\boldsymbol{Z}$ allocate each fixed or random effect to their corresponding observation in $\mathbf{y}$ (Isik et al. 2017). For each model no fixed effects were added, so $\boldsymbol{X} \boldsymbol{b}$ reduces to the mean vector. Random effects that were normal, independent and identically distributed $\sim \operatorname{NIID}\left(0, \sigma_{\text {effect }}^{2}\right)$ were included for site-year combination, multiple measurements for each genet representing observations across years, and a nugget effect for residual error variance. A random term for genet was included that had a mean 0 and a known variance-covariance matrix of the genomic relationship matrix $(\mathrm{GRM}) \sim(0$, $\sigma_{\text {genet }}^{2}$ GRM), which explained the genet effect that accounts for the relationship between genets using the GRM (Isik et al., 2017 pg 124-125). The GRM was calculated as $\theta$ MM' where M is an matrix of marker scores with dimensions $n$ individuals by $m$ markers, and $\theta$ is a proportionality constant (Endelman and Jannink 2012). The GRM was computed with the A.mat function in the rrBLUP R package (Endelman 2011). Within the model, residual error was formed of two parts with the nugget being NIID and then a correlated error term for rows and columns (AR1 x AR1, autoregressive first order correlation structure) (Isik et al., 2017 pg 93; 217). A separate AR1 x AR1 structure was fit for each cycle-site-year combination (14 total combinations), with ASREML requiring a complete row column matrix, with any incomplete observations filled in with dummy variables. This model fit one BLUP per genet regardless of if a trait had been measured one or multiple times and will be referred to as combined analysis as all years and 
196 cycles of data observations were combined in one model. For some traits, convergence failed

197 using the AR1xAR1 model, and a reduced model with no row and column error structure was fit.

198 Eqn. 1 was also fit individually for each cycle-year combination by dropping terms for cycle-

199 year combination and repeated measurements across years.

Genomic Profiling

201 All genets were profiled using genotyping-by-sequencing (GBS) using a two enzyme protocol as

202 in Poland et al. (2012). DNA extraction and pooled 192-plex GBS libraries were prepared at

203 Kansas State University with all sequencing conducted at Hudson Alpha, Huntsville, AL using

204 Illumina HiSeq machines. Single nucleotide polymorphisms (SNPs) were scored using the

205 TASSEL GBSv2 pipeline (Glaubitz et al. 2014) and the Thinopyrum intermedium draft genome

206 reference sequence (prerelease access provided by Thinopyrum intermedium Genome

207 Sequencing Consortium). The IWG draft genome reference includes three sets of seven

208 chromosomes numbered 1-7 based on homology to the seven chromosomes of barley (Kantarski

209 et al. 2016). Chromosomes corresponding to three homoeologous groups (subgenomes) of IWG

210 were designated J1-J7, S1-S7, and V1-V7 based on homologies to possible diploid ancestors in

211 the prereleased Thinopyrum intermedium draft genome reference sequence (unpublished data). A

212 total of 123,423 putative SNPs were identified across the 6,824 genotyped genets. Filtering was

213 done based on four criteria. First, each SNP aligned to one unique location on one of the 21 main

214 chromosomes. Second, a minimum read depth of 4 tags was required to call a homozygous

215 genotype, while heterozygotes could be called with a minimum two contrasting tags for each

216 SNP. If the minimum read depth threshold was not met, the SNP site was set to missing. Third,

217 the maximum data missing per SNP was $70 \%$ and individual genets could not have more than

$21895 \%$ missing data. Fourth, SNPs must have a minor allele frequency (MAF) greater than 0.01.

219 After filtering, this dataset consisted of a total of 6,517 genets and 23,611 SNPs. Markers were

220 imputed with Beagle version 4.1 using the default parameters (Browning and Browning 2016).

Linkage Disequilibrium and Genetic Parameters

222 Linkage disequilibrium (LD) was evaluated using TASSEL version 5.2.3 (Bradbury et al. 2007)

223 for all pairwise comparisons within each chromosome. The Hill and Weir formula (Hill and Weir

224 1988) was fit using the $n l s$ function in $\mathrm{R}$ ( $\mathrm{R}$ Core Team 2020) to describe the extent of genome

225 and chromosome LD using $r^{2}$. The greater of the distance at which half of the maximum value of 
226 the fitted value occurred, or $r^{2}=0.1$ was considered the extent of LD (Flint-Garcia et al. 2003).

227 The fixation index $F_{S T}$ (Weir and Cockerham 1984) was used to evaluate population

228 differentiation among cycles and was calculated using the diveRsity $\mathrm{R}$ package (Keenan et al.

229 2013). Values of $F_{S T}>0.15$ were considered evidence of population differentiation whereas $F_{S T}$

$230<0.05$ was considered as no evidence of population divergence (Hartl \& Clark, 1997 pg 118-19).

232 The GWAS function in $r r B L U P$ (Endelman 2011) was used to assess marker-trait associations for 233 each set of phenotypic trait data both jointly and by cycle-year combination. The GWAS model 234 is a mixed-linear model (Yu et al. 2006) with the form:

$$
\boldsymbol{y}=\boldsymbol{X} \boldsymbol{\beta}+\boldsymbol{Z} \boldsymbol{g}+\boldsymbol{S} \boldsymbol{\tau}+\boldsymbol{e} \quad \text { Equation } 2
$$

236 where $\boldsymbol{y}$ is an $n \times 1$ vector of phenotypic observations (BLUPs from Eqn. 1), $\boldsymbol{\beta}$ is a $p \times 1$ vector 237 of fixed effects where $p$ is the number of fixed effects for population structure, $\mathbf{X}$ is an $n x p$ 238 design matrix for fixed effects, $\boldsymbol{g}$ is an $n \times 1$ vector of random polygenic effects, $\boldsymbol{Z}$ is an $n \times n$ 239 matrix that is the GRM, $\boldsymbol{\tau}$ is the fixed effect for a given marker being tested and $\boldsymbol{S}$ an $n \times 1$ 240 vector of marker scores for the respective locus, $\boldsymbol{e}$ is an $n \times 1$ vector of random residuals.

241 Population structure was accounted for by using the first six principal components $(p=6)$, and 242 model compression used 'population parameters previously determined' (P3D) (Zhang et al. 243 2010)

244 A total of 23,611 markers were tested for each trait, and markers with a significance threshold 245 above a 0.05 false discovery rate (FDR) (Storey and Tibshirani 2003) were considered 246 significant. The FDR was calculated using a modified function from in $r r B L U P$ R package 247 (Endelman 2011). Plots were created using the qqman R package (Turner 2017). For each 248 significant marker, marker effects were determined using the lmekin function from the coxme $\mathrm{R}$ 249 package (Therneau 2020) following the analysis of Sehgal et al. (2020). Percent variance 250 explained (PVE) was calculated following methods by Broman and Sen (2009 pg. 246). As there 251 were often more than one significant marker on the same chromosome, we used a minimum gap 252 threshold of 100MB between significant markers to distinguish and count unique QTL. Each 253 unique QTL was identified by the marker with the highest logarithm of the odds (LOD) value 
254 along with other significant markers not separated by at least $100 \mathrm{Mb}$, herein referred to as 255 associated markers.

256 Power analyses were completed using scripts from Wang and $\mathrm{Xu}$ (2019) where $\beta$ was set to 0.8.

257 Minimum detectable QTL effect sizes were determined based on sample size, relationship

258 between individuals, and heritability, where heritability was estimated from variance components 259 of Eqn 1 as:

261 where $\sigma_{g}^{2}$ is genet variance, $\sigma_{p}^{2}$ is phenotypic variance which is the sum of genet variance, 262 variance due to multiple observations, and residual error variance. The total number of QTL per 263 trait were estimated using a squared exponential distribution from Hall et al. (2016) according to 264 the formula:

$$
\boldsymbol{n}_{Q T L}=\frac{\boldsymbol{h}^{2}}{\mu_{d}-\sqrt{2 \mu_{d} \theta-\theta^{2}}} \quad \text { Equation } 4
$$

266 where $h^{2}$ is the heritability calculated from Eqn 2, $\mu_{d}$ is the average percent variance explained 267 by detected QTL, and $\theta$ is the lowest detectable QTL estimated from the power analysis. This 268 formula worked for all traits with detected QTL, but a minimum number of QTL for each trait 269 were estimated by dividing 1 by the smallest detectable QTL size. This provided a lower bound 270 on the number of QTL, regardless of if a QTL for any trait had been observed. Combining the 271 power analysis, which provided a minimum detectable PVE, the number of estimated QTL (Eqn.

272 4), and heritability we could estimate the size of the population required to detect QTLs

273 explaining a given level of the total genetic variance (Lynch and Walsh 1998; Hall et al. 2016).

274 For all analysis, we estimated the population size needed to detect QTLs accounting for 50\% of 275 the genetic variation.

277 All DNA sequence data has been deposited in the NCBI Sequence Read Archive (SRA)

278 (https://www.ncbi.nlm.nih.gov/bioproject/) as part of the umbrella BioProject PRJNA609325.

279 All scripts for data analysis and phenotypic data have been placed in the Dryad Digital 
280 Repository

281 (https://datadryad.org/stash/share/A6qr_cVxvh7suuju4V0CwXNMAD_Wvg7gQxaKChFJY6E).

282 


\section{RESULTS}

284 We assessed four TLI IWG breeding cycles that comprised approximately 4,200 genets and five 285 years of phenotypic data to dissect quantitative traits and inform breeding decisions. A linear

286 mixed model was used to account for multiple years of phenotypic observations and develop 287 BLUPs, leveraging data collected within the breeding program to better understand IWG 288 improvement. While a total of 34 different traits were observed across years (Supporting 289 Information Table S1) the primary traits of selection were shattering, free-threshing seed, seed 290 mass, and seed yield. Across cycles seed mass and shattering were positively correlated with 291 spike yield, while a negative association was generally observed between free threshing and 292 spike yield (Supporting Information Figures 1-4).

294 We evaluated the extent of linkage disequilibrium (LD) up to distance of $200 \mathrm{Mb}$, which is 295 substantially less than the size of most IWG chromosomes. Within the population LD declined 296 relatively rapidly, with genome-wide LD extending an average of $305 \mathrm{~kb}$ (Fig. 1). For individual 297 chromosomes the half decay distance for $r^{2}$ ranged from less than $1 \mathrm{~kb}$ up to $1.43 \mathrm{Mb}$ with 298 chromosome S3 having the shortest LD and chromosome J3 the longest LD. Even though 299 average LD declined rapidly, there were numerous marker combinations that maintained LD at 300 larger distances up to $50 \mathrm{Mb}$ (Fig. 1). 
(a).

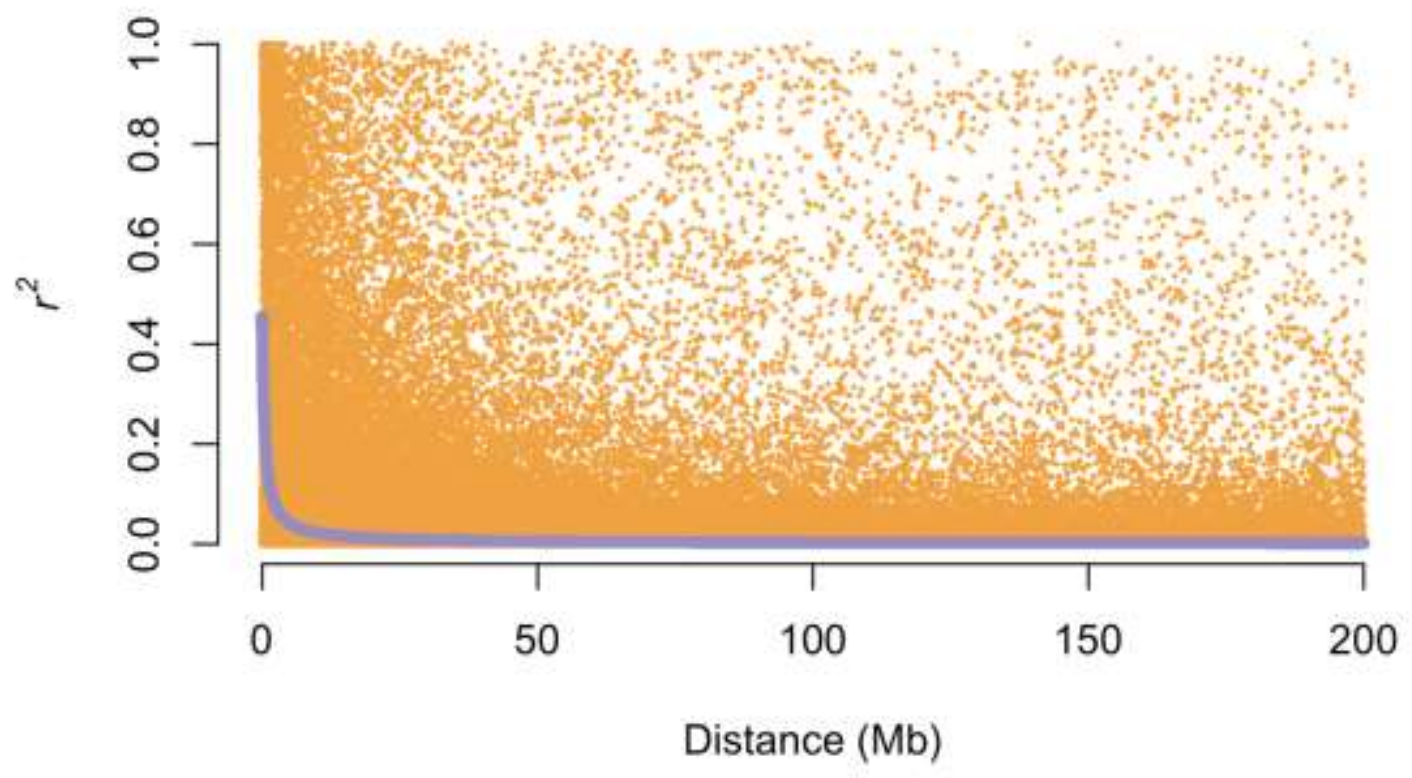

(b).

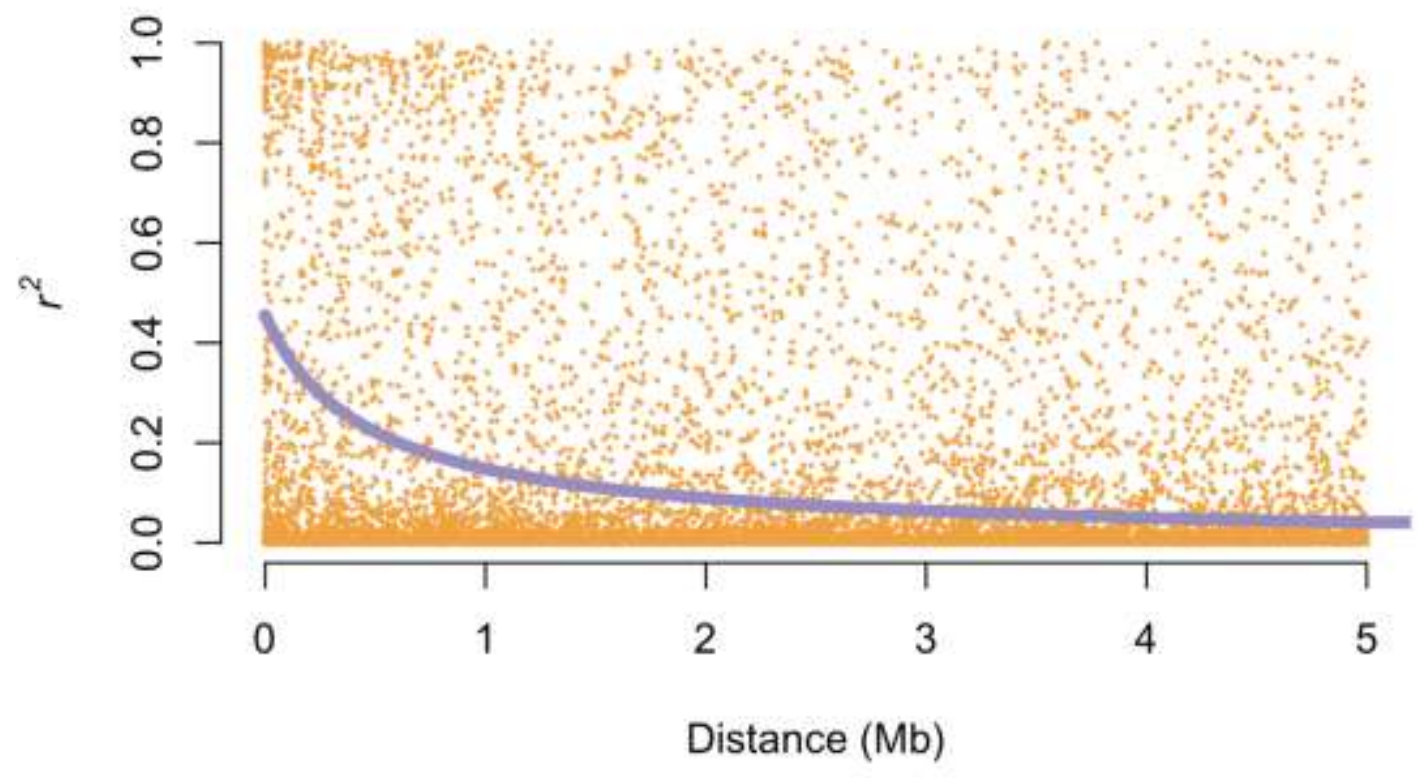

304 Fig. 1 genome-wide linkage disequilibrium (LD) for intermediate wheatgrass (Thinopyrum the Hill and Weir formula (1988) and shown in blue 
309 We used a genome-wide association analysis to identify the location, number, and size of QTL

310 underlying traits of interest to the IWG breeding program. Across all traits, the combined

311 analysis found 93 marker-trait associations for 16 different traits, representing 37 separate QTL

312 (Supporting Information Table 2). Of the traits of most interest to the breeding program—spike

313 yield, free threshing, seed mass, and shattering — only QTL were identified for shattering (floret

314 and brittle rachis) and free threshing. Both brittle rachis and free threshing had more than one

315 QTL on the same chromosome (J3 and V2 respectively, Table 1 and Figure 2). These effects

316 were small, explaining 1.0-2.7\% of the observed variation with allele effects ranging from -0.13

317 to 0.11 units less shattering on a 5 point scale and up to 4.6 percentage points less free threshing

318 on a 100 point scale for the alternate alleles compared to the reference genome (Table 1 and

319 Supporting Information Table S2)

320 We found evidence for brittle rachis QTL which impacts shattering on chromosome J3 (Fig. 2),

321 where the most significant marker (J3_122986862) was 5.6 Mb from IWG brittle rachis 2 (Btr2)

322 gene (Pourkheirandish et al. 2015) while another significant marker (J3_115931563, LOD =

323 8.47) was only 217 bp away from a Btr2 gene. This QTL region was identified both in the

324 combined analysis and analysis across individual cycles and years (Supporting Information

325 Table 2) and was supported by up to 17 associated markers above the genome-wide threshold

326 (Fig. 2).

327 Seed circularity had the most significant markers of any trait in the combined analysis, with 23

328 loci representing eight unique QTL located across seven different chromosomes (Fig. 2,

329 Supporting Information Table S2). For the number of florets per spike and florets per spikelet,

330 one QTL region overlapped with colocalized markers on chromosomes J5 having the same

331 directional effects (Supporting Information Table S2). One QTL for FSU was identified on

332 chromosome S5.

333 Along with analyzing the combined data, each cycle-year combination was analyzed

334 independently. This resulted in 209 significant markers representing 67 unique cycle-year QTL

335 being observed across 20 different traits (Supporting Information Table S2). Many of these QTL

336 signals were similar to the combined analysis that the QTL had several, up to 26, associated 
337 markers per QTL. Taken together, all analysis revealed QTL associations across 19 of the 21

338 chromosomes of IWG, with many chromosomes harboring QTL for multiple traits (Supporting

339 Information Table S3).

340 Across 34 traits and up to nine cycle-year combinations, all of the identified loci using the joint

341 analysis explained minimal variation, with 5.2\% percent variation explained (PVE, stem

342 diameter) being the maximum for any combined analysis with an average of $1.7 \%$ PVE per

343 identified QTL. When considering markers identified by cycle-year analysis, the PVE were

344 greater than the combined analysis, yet only 14 of the 209 markers had PVE > 10\%. 
346

Table 1 Significant quantitative trait loci (QTL) associations in The Land Institute intermediate wheatgrass (Thinopyrum intermedium) breeding program for priority traits

\begin{tabular}{|c|c|c|c|c|c|c|c|c|c|c|c|c|c|c|c|c|}
\hline Trait & QTL \# & $\begin{array}{l}\text { Associated } \\
\text { markers }\end{array}$ & Chr & Position & $\mathbf{n}$ & LOD & $\mathbf{F}_{\mathrm{ST}}$ & PVE & $\begin{array}{l}\text { Ref/ } \\
\text { alt }\end{array}$ & MAF & $\begin{array}{l}\text { Ref } \\
\text { value }\end{array}$ & $\begin{array}{l}\text { Ref } \\
\text { SE }\end{array}$ & $\begin{array}{l}\text { Alt } \\
\text { value }\end{array}$ & Alt SE & Het value & Het SE \\
\hline \multirow{4}{*}{ Brittle rachis } & 1 & 17 & $\mathrm{~J} 3$ & 122986862 & 1441 & 8.51 & 0.01 & 2.7 & $\mathrm{~A} / \mathrm{G}$ & 0.38 (A) & 0.93 & 0.008 & 0.04 & 0.009 & 0.02 & 0.007 \\
\hline & 2 & 0 & $\mathrm{~J} 3$ & 421522694 & 1050 & 4.71 & 0.08 & 2.0 & $\mathrm{G} / \mathrm{T}$ & $0.37(\mathrm{~T})$ & 0.98 & 0.008 & -0.05 & 0.014 & -0.02 & 0.008 \\
\hline & 1 & 1 & S3 & 132131062 & 1653 & 5.32 & 0.06 & 1.5 & $\mathrm{C} / \mathrm{G}$ & $0.34(\mathrm{G})$ & 0.95 & 0.005 & 0.05 & 0.009 & 0.03 & 0.005 \\
\hline & 1 & 0 & S5 & 391487396 & 1659 & 4.58 & 0.00 & 1.3 & $\mathrm{~T} / \mathrm{C}$ & $0.34(\mathrm{~T})$ & 0.98 & 0.008 & -0.03 & 0.005 & -0.01 & 0.005 \\
\hline \multirow{2}{*}{ Free threshing } & 1 & 0 & V2 & 196007664 & 2867 & 5.95 & 0.08 & 1.0 & $\mathrm{G} / \mathrm{T}$ & $0.20(\mathrm{~T})$ & 55.53 & 0.158 & -3.34 & 0.649 & -1.50 & 0.351 \\
\hline & 2 & 0 & V2 & 357856894 & 1478 & 6.11 & 0.12 & 1.9 & $\mathrm{~T} / \mathrm{G}$ & $0.18(\mathrm{G})$ & 55.93 & 1.103 & -4.65 & 0.963 & -1.79 & 0.846 \\
\hline \multirow{4}{*}{ Shattering } & 1 & 0 & $\mathrm{~J} 2$ & 636725449 & 1359 & 4.58 & 0.00 & 1.5 & $\mathrm{C} / \mathrm{T}$ & $0.17(\mathrm{~T})$ & 2.19 & 0.010 & -0.13 & 0.039 & -0.08 & 0.021 \\
\hline & 1 & 6 & S2 & 441397840 & 3130 & 10.60 & 0.01 & 1.5 & $\mathrm{~T} / \mathrm{C}$ & $0.47(\mathrm{~T})$ & 2.13 & 0.015 & 0.10 & 0.008 & 0.04 & 0.009 \\
\hline & 1 & 1 & S4 & 341952545 & 2204 & 5.90 & 0.22 & 1.2 & $\mathrm{G} / \mathrm{C}$ & $0.46(\mathrm{C})$ & 2.20 & 0.023 & -0.08 & 0.015 & -0.02 & 0.013 \\
\hline & 1 & 2 & S5 & 380535059 & 1620 & 4.96 & 0.00 & 1.4 & $\mathrm{~T} / \mathrm{A}$ & 0.25 (A) & 2.16 & 0.030 & 0.11 & 0.027 & 0.08 & 0.023 \\
\hline
\end{tabular}

Marker with highest LOD reported for each QTL; QTL \#, number of QTL per chromosome; Associated markers, number of significant markers associated with each QTL; Chr, chromosome; n, number of individuals observed; $F_{S T}$ fixation index between The Land Institute (TLI) Cycle 6 and TLI Cycle 9; PVE, percent variance explained; Ref/alt reference and alternate allele respectively; MAF, minor allele frequency for combined TLI Cycles 6-9 with minor allele in parenthesis; Ref value, reference allele value for a trait, Ref SE, standard error of reference value; Het, heterozygous 

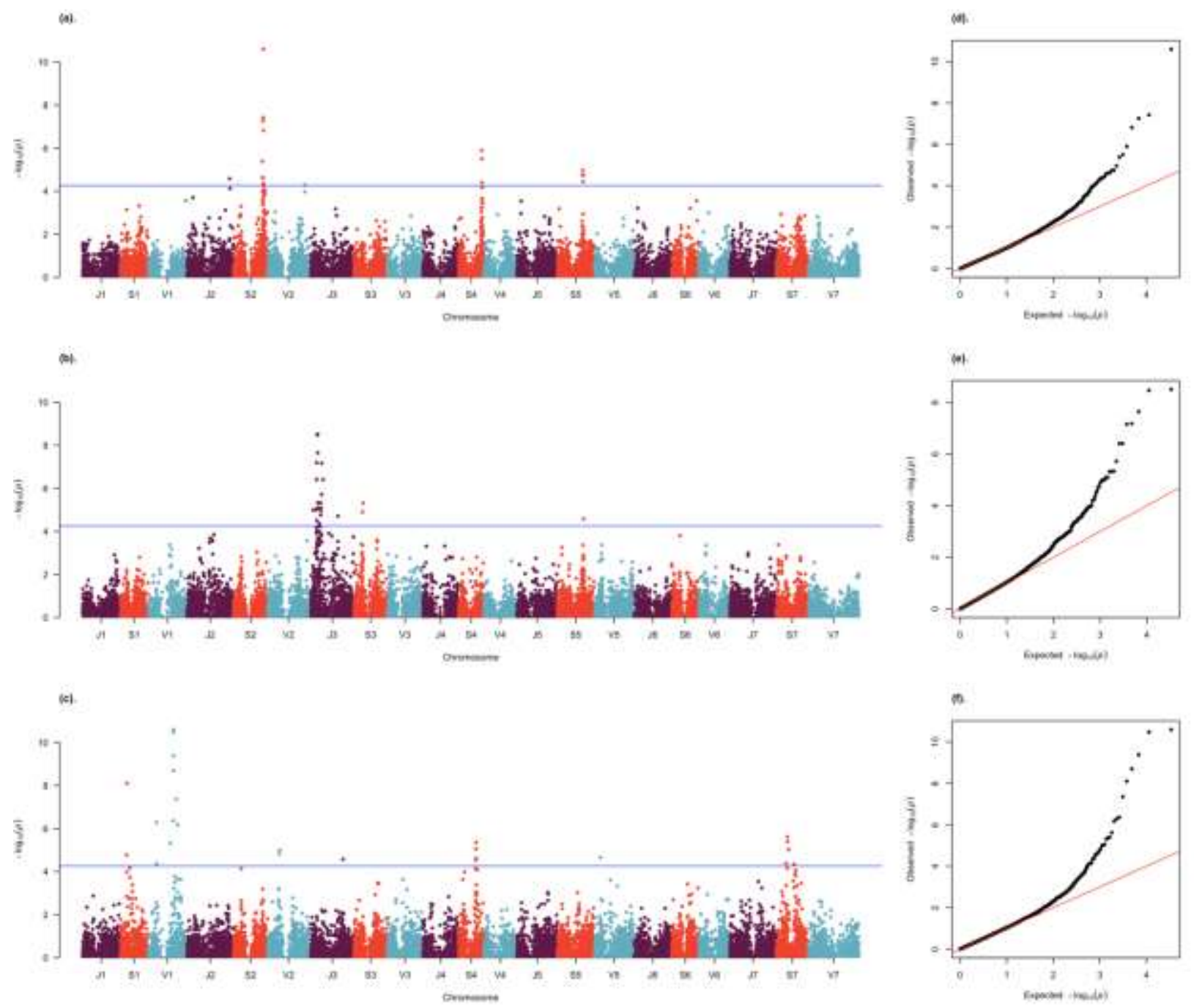

358

359

360

361

362

363

364

365

366
Fig. 2 Manhattan plots of (a) shattering, (b) brittle rachis, and (c) seed circularity in intermediate wheatgrass (Thinopyrum intermedium) with line indicating 0.05 false discovery rate. Panels d, e and $\mathbf{f}$ show quantile-quantile (QQ) plots for $\mathrm{p}$ values under the null hypothesis (no association) and observed $p$ values for brittle rachis (d), shattering (e), and seed circularity (f), respectively 
368 To evaluate the genetic architecture of these domestication and agronomic traits, we estimated 369 the number of effective QTL for each trait using results from our power analysis, heritability, 370 and QTL analysis. In general, our analysis of this breeding germplasm had the ability to detect 371 small QTL, with PVE of the smallest detectable QTL ranging from 0.7 to $3.0 \%$ for each trait 372 (Table 2). Determining the smallest detectable QTL also provided a lower bound estimate of the 373 minimum number of QTL for each trait which ranged from 33 to 149 (Table 2) regardless of 374 whether we had detected QTL. For traits with detected QTLs, we estimated the number of QTL 375 for a given trait (using Eqn. 4) which ranged from 93 to 357 (Table 2) for combined analysis. 376 Using each cycle-year combination, a range of QTL could be estimated for traits with detected 377 QTL. For important traits such as shattering, the estimated number of QTL ranged from 97 to 378258 , brittle rachis could be controlled by up to 293 QTL, and free threshing could have as few as 37939 QTL. While the reported number of QTL could vary greatly within and between traits, these 380 estimates demonstrate that these traits are highly polygenic and controlled by many loci.

381 We also estimated the population size, that would be required to detect QTLs explaining $50 \%$ of 382 the genetic variation. Population size differed between traits, ranging from a minimum of 98 up 383 to 15,931 plants with an average population size of 1720 (Table 2). For priority breeding traits of 384 spike yield, reduced shattering, and seed mass, the minimum population sizes, to detect QTLs 385 explaining $50 \%$ of the genetic variance, were all $>2500$ plants. 
387 Table 2 Number of estimated quantitative trait loci (QTL) for phenotypic traits in intermediate wheatgrass, and the estimated

388 population size to needed to detect QTLs explaining 50\% of the genotypic variance

\begin{tabular}{|c|c|c|c|c|c|c|c|c|c|}
\hline Trait & $\begin{array}{c}\text { Smallest } \\
\text { detectable QTL } \\
\text { in percent } \\
\text { variance } \\
\text { explained } \\
\end{array}$ & $\begin{array}{c}\text { Minimum } \\
\text { number } \\
\text { of QTL }\end{array}$ & $\begin{array}{c}\text { QTL } \\
\text { estimate } \\
\text { based on } \\
\text { Hall et al. } \\
\text { (2016) } \\
\end{array}$ & $\begin{array}{l}\text { Minimum } \\
\text { QTL for } \\
\text { individual } \\
\text { cycle year } \\
\text { combinations }\end{array}$ & $\begin{array}{l}\text { Maximum } \\
\text { number of } \\
\text { QTL for } \\
\text { individual } \\
\text { cycle year } \\
\text { combinations }\end{array}$ & $\begin{array}{c}\text { Number of } \\
\text { cycle-year } \\
\text { combinations } \\
\text { with } \\
\text { observed } \\
\text { QTL } \\
\end{array}$ & $\mathbf{h}^{2}$ & $\begin{array}{c}\text { Minimum } \\
\text { population } \\
\text { size }\end{array}$ & $\begin{array}{c}\text { Maximum } \\
\text { population } \\
\text { size }\end{array}$ \\
\hline Brittle rachis & 0.9 & 111 & 166 & 18 & 293 & 4 & 0.44 & 624 & 7339 \\
\hline Flag leaf height $(\mathrm{cm})$ & 3.0 & 34 & & & & & 0.44 & 1042 & \\
\hline Flag leaf length $(\mathrm{cm})$ & 2.8 & 36 & & 5 & & 1 & 0.31 & 212 & 1522 \\
\hline Flag leaf width (mm) & 2.8 & 36 & & 84 & & 1 & 0.62 & 755 & 1633 \\
\hline Free threshing & 0.7 & 147 & 304 & 39 & & 1 & 0.63 & 809 & 5343 \\
\hline Lodging & 1.3 & 76 & & & & & 0.38 & 2433 & \\
\hline maturity & 0.7 & 147 & & 6 & 221 & 2 & 0.5 & 281 & 5055 \\
\hline Number of florets per spike & 0.9 & 110 & 214 & & & & 0.23 & 5592 & 10380 \\
\hline Number of florets per spikelet & 0.9 & 110 & 177 & & & & 0.25 & 5057 & 7919 \\
\hline Peduncle width (mm) & 2.4 & 42 & 289 & 303 & & 1 & 0.52 & 1004 & 6472 \\
\hline Floret site utilization & 0.9 & 109 & 236 & 101 & & 1 & 0.75 & 1572 & 3578 \\
\hline Plant height $(\mathrm{cm})$ & 0.7 & 149 & & 14 & 558 & 3 & 0.38 & 627 & 15931 \\
\hline Seed area $(\mathrm{mm} 2)$ & 0.7 & 147 & & 4 & 22 & 2 & 0.69 & 93 & 2428 \\
\hline Seed density & 0.7 & 147 & 133 & & & & 0.45 & 3398 & 3737 \\
\hline Seed image circularity & 0.7 & 144 & 239 & 16 & 88 & 4 & 0.52 & 475 & 4948 \\
\hline Seed length (mm) & 0.7 & 147 & 251 & 113 & & 1 & 0.58 & 2298 & 4864 \\
\hline Seed mass (mg) & 0.7 & 147 & & & & & 0.63 & 2732 & \\
\hline Seed perimeter $(\mathrm{mm})$ & 2.7 & 37 & & & & & 0.79 & 613 & \\
\hline Seed width $(\mathrm{mm})$ & 0.7 & 147 & 126 & 14 & 115 & 3 & 0.36 & 628 & 4550 \\
\hline Seeds per spike & 0.7 & 148 & & & & & 0.42 & 3972 & \\
\hline Shattering & 0.7 & 148 & 187 & 97 & 258 & 6 & 0.4 & 2823 & 7139 \\
\hline Spike dry weight (g) & 0.9 & 110 & & & & & 0.36 & 3625 & \\
\hline Spike emergence $(\mathrm{cm})$ & 2.3 & 43 & 283 & 266 & & 1 & 0.51 & 1064 & 6102 \\
\hline Spike emergence $\%$ & 1.4 & 74 & 357 & & & & 0.51 & 1770 & 7645 \\
\hline Spike harvest index & 0.9 & 110 & & & & & 0.32 & 3961 & \\
\hline Spike length (cm) & 1.3 & 78 & 268 & 547 & & 1 & 0.49 & 1890 & 12297 \\
\hline Spike yield (g) & 0.7 & 148 & & & & & 0.53 & 3231 & \\
\hline Spikelet density & 2.7 & 37 & & 21 & & 1 & 0.63 & 482 & 777 \\
\hline Spikelets per spike & 0.9 & 110 & 101 & 14 & & 1 & 0.25 & 948 & 5153 \\
\hline Stem angle & 1.3 & 79 & & & & & 0.59 & 1586 & \\
\hline Stem diameter $(\mathrm{mm})$ & 2.9 & 35 & 93 & 50 & & 1 & 0.51 & 897 & 2197 \\
\hline Stem strength bottom & 3.0 & 33 & & 30 & & 1 & 0.45 & 934 & 979 \\
\hline Stem strength middle & 1.3 & 75 & & 8 & & 1 & 0.3 & 515 & 3049 \\
\hline Stem strength top & 3.0 & 33 & & & & & 0.77 & 552 & \\
\hline
\end{tabular}

390 Maximum population size only calculated if more than one number of QTL estimate available. 
393 Using all markers, fixation index, $F_{S T}$, was calculated to examine the potential impact of 394 directional selection which would generation genetic differentiation between TLI-Cycle 6 and 9. 395 Only $548(2.3 \%)$ of these markers showed high or very high genetic differentiation, suggesting 396 that many areas of the genome have not been under consistent selection pressure (Table 3). Of 397 the 72 markers that showed very high genetic differentiation, they were distributed across 20 of 398 the 21 chromosomes. For significant loci identified by GWAS, allele frequency and $F_{S T}$ were 399 used to further evaluate changes between TLI breeding cycles 6 and 9. As direct selection should 400 alter allele frequency, we expected this analysis to provide evidence of selection pressure. Of the 401 significant MTAs identified, only 10 markers (4.5\%) had $F_{S T}$ values $>0.15$ (Table 4).

402 Of 24 traits with MTA, only three traits—seed circularity, shattering, and seed length—showed $403 \quad F_{S T}>0.15$ for any single trait associated marker. For shattering, a trait that has been under strong 404 selection, two markers on chromosome S4 had high $F_{S T}$ values (Fig. 3) and the other associated 405 markers on chromosome S4 had moderate $F_{S T}$ values. For this trait, all other significant markers 406 on chromosomes $\mathrm{J} 2, \mathrm{~S} 1, \mathrm{~S} 2, \mathrm{~S} 3, \mathrm{~S} 5$, and V2 did not show any significant differentiation $\left(F_{S T}<\right.$ 4070.05 ) after 3 cycles of selection based on $F_{S T}$ values. The high $F_{S T}$ value of marker 408 S04_341952545 resulted in the alternate allele frequency increasing from $26 \%$ to $60 \%$, 409 corresponding to a -0.08 unit decrease in shattering over three cycles of selection (Fig. 3, Table 410 4). Compared to the $2.3 \%$ of genome-wide markers that showed high differentiation, up to $6.4 \%$ 411 of the shattering markers had high $F_{S T}$ values.

412 The marker J03_115931563, which had a strong association with brittle rachis had a moderate $413 F_{S T}$ value of 0.11. Surprisingly, from TLI-cycle 6 to TLI-cycle 9 the frequency of the favorable 414 (reference) allele actually decreased from $28 \%$ to $7.5 \%$, in the opposite direction as expected by 415 selection for reduced shattering. Evaluating this locus for all other traits showed that the 416 reference allele while favorable for shattering and free threshing was detrimental to spike yield, 417 seeds spike ${ }^{-1}$, and spike dry weight. This suggest that there is tradeoff between spike yield and 418 brittle rachis at this locus and that selection for increased yield could be driving the alternate 419 allele. 
420 In addition to shattering, high $F_{S T}$ values were observed for seed circularity and seed length at the 421 locus V01_438389996. This marker showed the reference allele frequency changed from 0.69 to 4220.96 over the four cycles, corresponding to a decrease in seed circularity and increase in seed 423 length, i.e. a more elongated seed. Even though significant markers were identified for number of 424 florets per spike, florets per spikelet, spikelets per spike, and FSU-yield component traits - all 425 markers except for one showed little differentiation across the four cycles of selection. Even for 426 the priority trait of free threshing, only two of 10 markers (20\%) showed moderate 427 differentiation. The $F_{S T}$ values for markers associated with plant height, which has not been 428 targeted by selection, did not show any differentiation. 
429 Table 3 Fixation index, $F_{S T}$, values for all single nucleotide polymorphisms (SNPs) in The Land Institute intermediate wheatgrass 430 breeding population cycles 6 and 9

431

\begin{tabular}{llllll}
\hline & & \multicolumn{4}{c}{ Number of loci $(\%)$} \\
\cline { 3 - 6 } $\begin{array}{l}\text { Level of } \\
\text { differentiation }\end{array}$ & $\begin{array}{l}\text { Range of } \boldsymbol{F}_{\boldsymbol{S} T} \\
\text { values }\end{array}$ & Genome-wide & Shattering & Seed circularity & Brittle rachis \\
\hline Little & $0.00-0.05$ & $18258(77.3)$ & $26(83.9)$ & $26(60.4)$ & $44(78.6)$ \\
Moderate & $0.05-0.15$ & $4805(20.3)$ & $3(9.7)$ & $16(37.2)$ & $12(21.4)$ \\
High & $0.15-0.25$ & $476(2.0)$ & $2(6.4)$ & $1(2.3)$ & 0 \\
Very High & 0.25 & $72(0.3)$ & 0 & 0 & 0 \\
\hline Total & & 23611 & 31 & 43 & 56 \\
\hline
\end{tabular}

432 Level of differentiation of $F_{S T}$ values are from Hartl and Clark (1997). 
433 Table 4 Biallelic reference allele frequency for four breeding cycles in The Land Institute breeding program that had Fixation index, $434 F_{S T}$, greater than 0.15

435

\begin{tabular}{|c|c|c|c|c|c|}
\hline Trait & Marker & Cycle 6 & Cycle 7 & Cycle 8 & Cycle 9 \\
\hline Shattering & S04_341952545 & 0.74 & 0.58 & 0.42 & 0.40 \\
\hline Shattering & S04_349886731 & 0.74 & 0.51 & 0.41 & 0.45 \\
\hline Seed circularity \& seed length & V01_438389996 & 0.69 & 0.78 & 0.84 & 0.96 \\
\hline
\end{tabular}


(a).

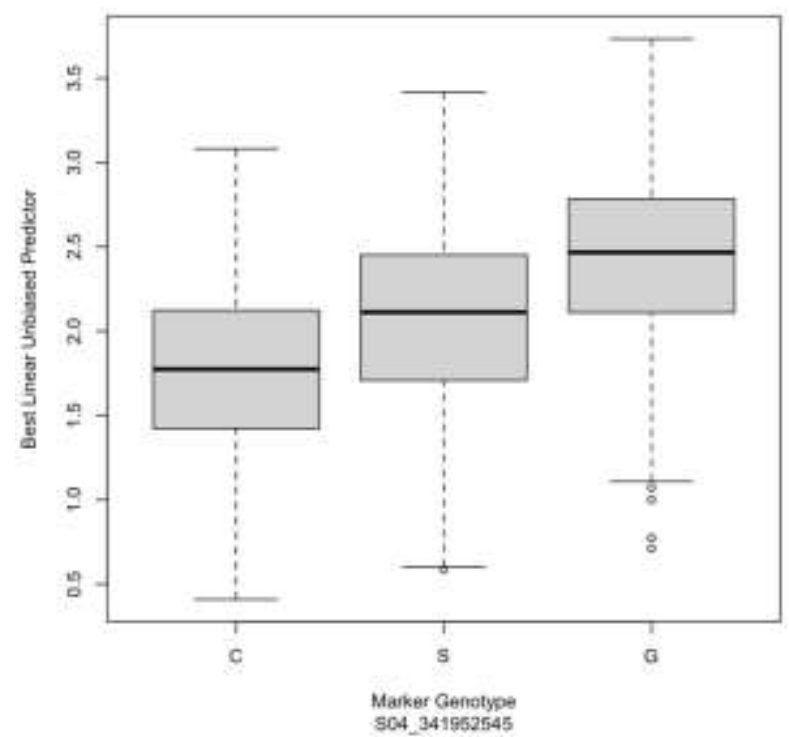

(b).

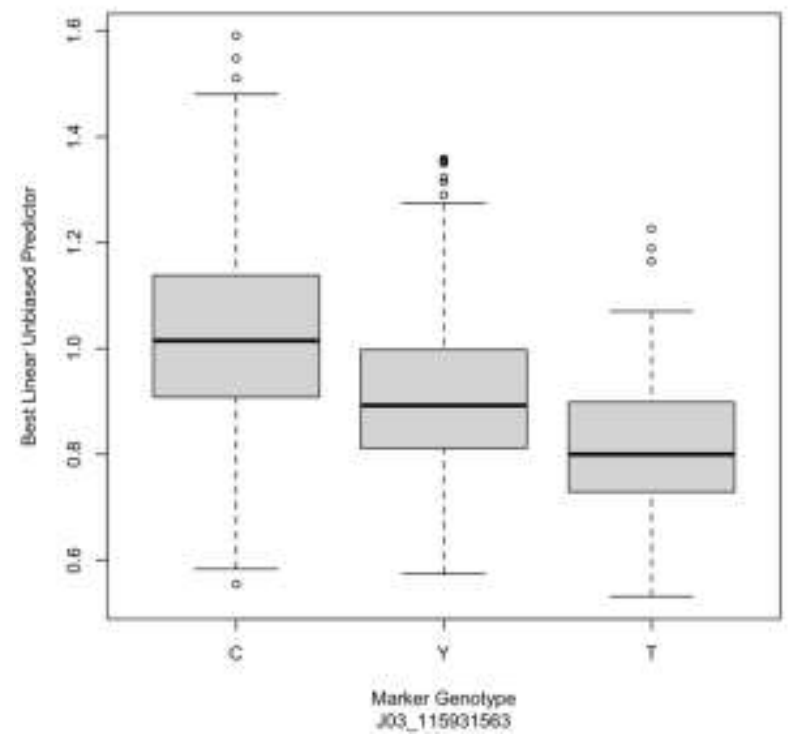

(c).

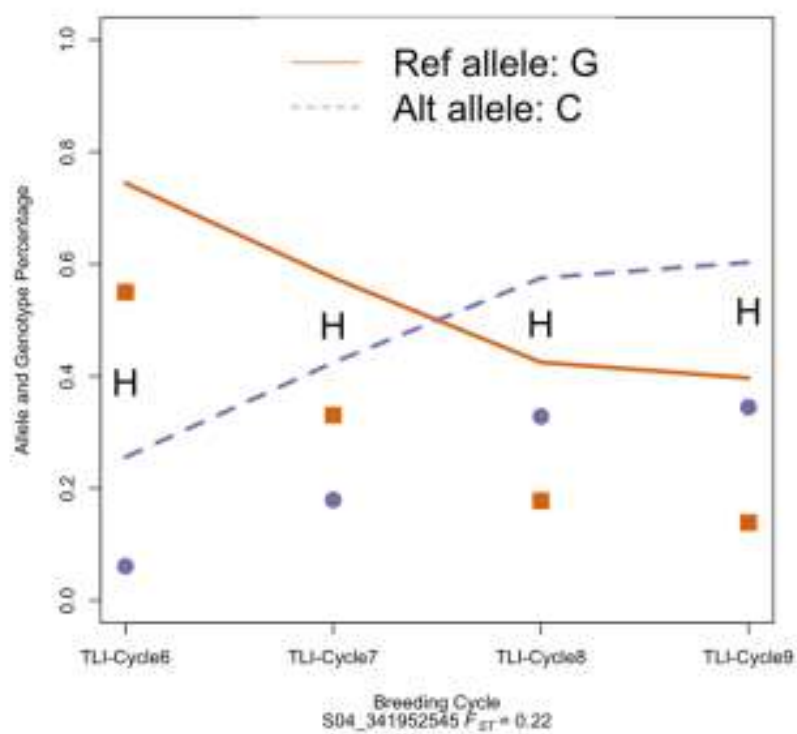

(d)

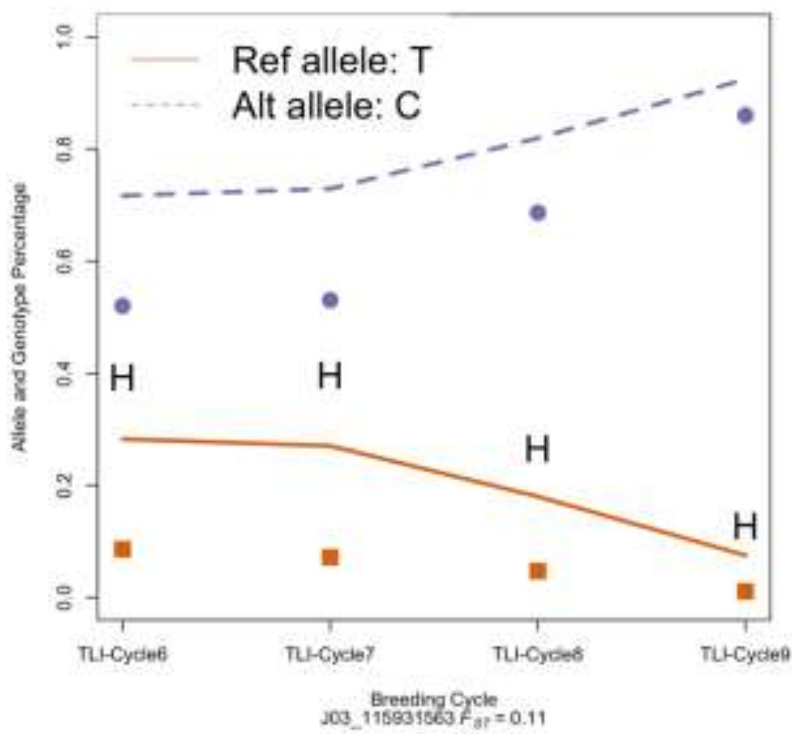

Fig. 3 Distribution of phenotypic values for shattering and brittle rachis (a and $\mathbf{b}$ respectively), where lower values are preferred, at the marker loci S04_341952545 and J03_115931563 in intermediate wheatgrass (Thinopyrum intermedium). Panels $\mathbf{c}$ and $\mathbf{d}$ displays the allele (line plots) and genotype (points, $\mathrm{H}$ is heterozygote) frequency change for the shattering marker in The Land Institute (TLI) Cycle 6 to 9 breeding populations, population differentiation expressed with $F_{S T}$ between TLI Cycle 6 and TLI Cycle 9 


\section{DISCUSSION}

448 The TLI IWG breeding program has completed four cycles of breeding since 2017 using GS

449 with current evidence suggesting that genetic gains can exceed $8 \%$ year $^{-1}$ for spike yield and up 450 to $14 \%$ year $^{-1}$ for free threshing (Crain et al. 2021a). Given the magnitude of the challenges to 451 domesticate a new crop, identifying genomic regions controlling traits should be a priority within 452 breeding programs as a means to accelerate gains. As such, we used breeding data to complete 453 GWAS analysis for 34 traits. While many markers were identified, there appeared to be little 454 consistency from one cycle-year combination to the next, suggesting genotype by environment 455 interaction between years. Additionally, the PVE explained by markers evaluating cycle by year 456 combinations were generally higher than the combined analysis, ranging from 2 to $15 \%$, 457 suggesting that the exclusion of environmental variance within these models are upwardly biased 458 because of truncation of QTL below the detectable threshold (Beavis 1994; Xu 2003).

459 Brittle rachis had significant MTAs, but until 2019 this trait was not considered separate from 460 shattering and not measured extensively in the population until 2020. As this marker is 461 associated with a known gene-Btr2 - and has been found in other IWG populations (Altendorf 462 2020), it is a prime candidate for the TLI breeding program to select and drive to fixation over 463 the next few cycles. While our data did not show this locus associated with any other trait, work 464 by Larson et al. (2019) identified traits including spikelets per spike, seeds per spikelet, seed 465 area, and spike length on this chromosome which could explain the reduction of the favorable 466 allele for brittle rachis.

467 Even though we evaluated 34 traits, very few significant associations were found, including for 468 spike yield and seed mass, which have been a primary target of selection. Leveraging the large 469 number of observations, we estimated the effective number of QTL in the population. While the 470 estimations hinge on a number of assumptions including QTL distribution (Otto and Jones 2000), 471 additive genetic effect, and random segregation (Hall et al. 2016), they provide an approximation 472 of the complexity of given traits. Considering the ability to detect small QTL, that explained only

$473 \quad 0.7 \%$ of the variation, and the large number of minimum QTL estimated, there appear to be no 474 large effect QTL that can be targeted by marker-assisted selection for IWG improvement. The 
475 apparent deficiency of large effect QTL could indicate that the intense selection bottleneck of 476 IWG from 14 plants (Zhang et al. 2016) essentially fixed major allele effects in early generations 477 or that large effect genes were not in the founder population. Even though research shows 478 estimated genetic gains for spike yield of up to $8 \%$ year $^{-1}$ in TLI-Cycle 7-8 (Crain et al. 2021a) it 479 appears that these gains are from small effect loci. It should be noted that selection within the 480 breeding program was based on GS values and not on any particular marker per se. This 481 information suggest that the current breeding material has highly polygenic traits that follow an 482 infinitesimal model (Fisher 1918; Barton et al. 2017). Interestingly, we identified that 2.3\% (548 483 markers) had diverged between TLI-cycle 6 and 9, yet only four of the 217 MTAs showed high 484 or very high $F_{S T}$. Since genomic selection has been exclusively used for the last four breeding 485 cycles (Crain et al. 2021a), we evaluated the genome-wide estimated marker effects for yield 486 traits. Of the 72 highly diverged markers, 60\% and 56\% (43 and 40 markers respectively) had 487 coefficients with higher spike yield and seed mass and the mean of all these markers indicated 488 selection was in the favorable direction. As the IWG breeding continues, improvement will be from selecting on many small effect alleles.

491 Linkage disequilibrium was evaluated across the IWG genome. Within this IWG population, LD 492 declines rapidly relative to closed breeding populations and half-decay rarely exceeded $1 \mathrm{Mb}$ for 493 any chromosome. In comparison to annual wheat which has LD estimated to be $50 \mathrm{Mb}$ (Juliana 494 et al. 2018), LD is 160 fold lower necessitating more markers to cover the genome. If markers 495 were evenly spaced over the 12.75 Gb IWG genome (Vogel et al. 1999) a minimum of 42,000 496 markers would be needed to ensure all parts of the genome were in LD with a marker to increase 497 mapping resolution. While we leveraged a high-quality draft genome reference sequence, it is 498 possible that our results are influenced by the current genome assembly. It is possible that some 499 of the significant marker positions will change, providing a more complete picture of trait 500 observations and LD dynamics. As sequencing cost decreases and technology improves whole 501 genome sequencing or skim-sequencing approaches could provide an exponential increase in 502 markers to detect genomic associations (Jensen et al. 2020; Pavan et al. 2020).

503 While LD is estimated to decline rapidly, it should be noted that many of our significant GWAS 504 hits had multiple markers extending beyond the expected LD. This could indicate that selection 
505 has created larger linkage blocks. In maize, another outcrossing species, LD in diverse lines is 506 estimated to extend less than $1 \mathrm{~kb}$ (Tenaillon et al. 2001) to over $100 \mathrm{~kb}$ in elite maize lines

507 (Rafalski 2002), showing the extent that selection and narrow sets of germplasm can increase the 508 LD block size. As GS has been the method of selection in cycles 7 through 9, this could be 509 creating larger LD blocks for areas that are captured in the genome model. This would include 510 both traits under direct selection such as spike yield as well as any trait that indirectly contributes 511 to priority traits. It is also likely that there are different historical sources of LD, including LD 512 that existed in nature, LD created between the time of collection and the initial bottleneck of 513 selection at the Rodale Institute, and LD created in the TLI breeding program (Zhang et al. 2016; 514 DeHaan et al. 2018).

516 Within IWG, several other studies have evaluated important domestication and agronomic traits, 517 providing corroboration of key results. Studies have shown that IWG has strong collinearity with 518 the barley genome, (Kantarski et al. 2016; Zhang et al. 2016) providing resources to identify 519 candidate genes. Within a nested association mapping panel, Altendorf (2020) found the same 520 marker as this study for brittle rachis. While this marker is closest to a Btr2 gene, it is in a $7 \mathrm{Mb}$ 521 region with many btr-like genes (Pourkheirandish et al. 2015; Civáň and Brown 2017; DeHaan 522 et al. 2020). Using a bi-parental IWG population, Larson et al. (2019) investigated QTL for 523 domestication traits and found several overlaps with the current study. For seed shattering, 524 Larson et al. (2019) discovered QTL on chromosome J2 and S4 that align with results found in 525 this study. Chromosome S4 had the most significant seed shattering QTL (LOD > 15.0) in a full526 sib family derived from C3_3471, which has been described as the first non-shattering and free527 threshing IWG plant (Larson et al. 2019). There was also close alignment with free threshing 528 QTLs located on chromosome V2.

529 One of the most unanticipated results from this study was the large number markers associated 530 with seed circularity. One potential explanation is the effect of self-incompatibility genes, as 531 these have been shown to have an impact on seed size and fertility in a full-sib mapping 532 population of perennial ryegrass (Lolium perenne L.)(Studer et al. 2008). Self-incompatibility 533 (SI) in grasses is controlled by a two locus ( $S$ and $Z$ ) system (Lundqvist 1954; Cornish et al. 534 1979; Baumann et al. 2000), which are located on homoeologous groups 1 and 2 of IWG, 
respectively(Larson et al. 2019; Crain et al. 2020b). Self-incompatibility has been documented in

536 IWG (Dewey 1978; Jensen et al. 1990), and previously reported markers for seed area, seed

537 width, seed length, and seed weight by Zhang et al. (2017), Bajgain et al. (2019), and Larson et

538 al. (2019) are located near putative $S$ orthogenes on homoeologous group 1 of IWG. Although

539 the mechanism of SI is not completely characterized, Manzanares et al. (2016) demonstrated that

540 a domain of unknown function ( $S$-DUF247) is involved in SI reactions. This region has also been

541 associated with seed weight (Zhang et al., 2017; Larson et al. 2019), seed length (Bajgain et al.

542 2019), and was identified by Crain et al. (2020b) as an active SI locus in IWG. Regardless of

543 whether the loci related to seed circularity are related to potential SI activity or putative control

544 of seed circularity, these loci could be beneficial to the breeding program because seed shape

545 could have an impact on milling quality. Marshall et al. (1984) proposed that spherical seeds

546 maximize volume to surface ratio. IWG has very long and thin seeds (Zhang et al. 2017), so

547 selecting loci that alter seed shape could be used to both improve yield and end product use.

Application to Improving IWG

549 While we did not find any large effect QTL, our results suggest several potential applications

550 within the breeding program. Our data support that continued use of GS models for breeding and

551 selection is appropriate. While Bajgain et al. (2019) suggested using QTL as fixed effects in GS

552 models to improve predictions, none of our detected QTL explained more than $10 \%$ of the

553 variance, which would be large enough to be included as a fixed effect as suggested by Bernardo

554 (2014). Second, based on the QTL effect size, genetic mapping studies will require large

555 population sizes to accurately identify and estimate QTL. While the breeding program routinely

556 analyzes c 4,000 plants, this is probably the smallest number of plants needed for genetic

557 mapping based on our power analysis and assessment of genetic architecture for these key traits.

558 Lastly, selection pressure on traits that would indirectly enhance yield, such as the number of

559 florets per spike and florets per spikelet could be increased. Even though MTAs were identified

560 for some of these traits, current results showed minimal allele differentiation between TLI-Cycle

5616 and 9. The observed phenotypic variation of these traits suggest that GS can continue to be an

562 effective tool to improve these traits. Along with FSU, biomass production (Vico et al. 2016) and

563 seed set (Armstead et al. 2008) have been suggested as important steps in increasing perennial

564 seed production. 
565 By utilizing data generated within the breeding program, this study identified MTA for several 566 agronomic and domestication traits, all of which had small effects suggesting that traits are

567 highly polygenic. Even though no QTL were identified for spike yield and seed mass, several 568 QTL were found for component traits of yield, suggesting that genetic control of these traits is 569 from many small effect loci. Previous breeding efforts have increased spike yield by $77 \%$ and 570 seed mass by $23 \%$ over two breeding cycles (DeHaan et al. 2014). These results, coupled with 571 genetic gain estimates of over $8 \%$ year $^{-1}$ by Crain et al. (2021a), suggest that the current breeding 572 program has considerable variability, providing opportunity for continued improvement well into 573 the future. There appear to be few large effect QTL, with the substantial genetic progress having 574 been made through selection of genome wide loci with small effects. These observations support 575 a continued focus on classic breeding methods based on an underlying infinitesimal model of 576 genetic architecture (Fisher 1918; Barton et al. 2017) and further implementation of genomic 577 selection. The challenge of developing perennial grains is daunting, yet the knowledge generated 578 from this study will help select high yielding and high performing genets, leading to large scale 579 perennial grain crops. 


\section{ACKNOWLEDGEMENTS}

582 This work was funded in part by the Perennial Agriculture Project in conjunction with the

583 Malone Family Land Preservation Foundation and The Land Institute. Shuangye Wu provided

584 vital laboratory support, and Marty Christians provided invaluable field assistance. The

585 Thinopyrum intermedium Genome Sequencing Consortium provided prepublication access to the

586 IWG genome sequence. Computational work was completed on the Beocat Research Cluster at

587 Kansas State University, which is funded in part by NSF grants CNS-1006860, EPS-1006860,

588 and EPS-0919443. Contribution no. 22-046-J from the Kansas Agricultural Experiment Station.

\section{DECLARATIONS}

591 Funding This work was funded by The Perennial Agriculture Project, in conjunction with the

592 Malone Family Land Preservation Foundation and The Land Institute.

593 Conflicts of interest/Competing interest The authors declare that they have no conflict of 594 interest.

595 Availability of data and material Original sequence data has been uploaded to the NCBI

596 sequence read archive (SRA) (https://www.ncbi.nlm.nih.gov/bioproject/) as part of the umbrella 597 BioProject PRJNA609325.

598 Code availability R code generated for this study has been deposited in the Dryad digital

599 Repository, https://doi.org/10.5061/dryad.rbnzs7hb7

600 Authors' contributions JC, SL, LD and JP planned and designed the research. JC, SL, LD and 601 KD performed experiments, conducted fieldwork, and collected data. JC analyzed data. JC, SL, 602 LD, and JP wrote the manuscript.

603

604 


\section{REFERENCES}

606

607

608

609

610

611

612

613

614

615

616

617

618

619

620

621

622

623

624

625

626

627

628

629

630

631

632

633

634

635

636

637

638

639

640

641

642

643

644

645

646

647

648

649

Alonso MP, Mirabella NE, Panelo JS, et al (2018) Selection for high spike fertility index increases genetic progress in grain yield and stability in bread wheat. Euphytica 214:. https://doi.org/10.1007/s10681-018-2193-4

Altendorf KR (2020) Phenotypic and genetic characterization of domestication and yield component traits in the perennial grain crop intermediate wheatgrass. University of Minnesota

Altendorf KR, DeHaan LR, Heineck GC, et al (2021a) Floret site utilization and reproductive tiller number are primary components of grain yield in intermediate wheatgrass spaced plants. Crop Sci 61:1073-1088. https://doi.org/10.1002/csc2.20385

Altendorf KR, Larson SR, DeHaan LR, et al (2021b) Nested association mapping reveals the genetic architecture of spike emergence and anthesis timing in intermediate wheatgrass. G3 Genes|Genomes|Genetics 11:. https://doi.org/10.1093/g3journal/jkab025

Armstead IP, Turner LB, Marshall AH, et al (2008) Identifying genetic components controlling fertility in the outcrossing grass species perennial ryegrass (Lolium perenne) by quantitative trait loci analysis and comparative genetics. New Phytol 178:559-571. https://doi.org/10.1111/j.1469-8137.2008.02413.x

Bajgain P, Zhang X, Anderson JA (2020a) Dominance and G×E interaction effects improve genomic prediction and genetic gain in intermediate wheatgrass (Thinopyrum intermedium). Plant Genome 13:1-13. https://doi.org/10.1002/tpg2.20012

Bajgain P, Zhang X, Anderson JA (2019) Genome-wide association study of yield component traits in intermediate wheatgrass and implications in genomic selection and breeding. Genes|Genomes|Genetics g3.400073.2019. https://doi.org/10.1534/g3.119.400073

Bajgain P, Zhang X, Jungers JM, et al (2020b) 'MN-Clearwater', the first food-grade intermediate wheatgrass (Kernza perennial grain) cultivar. J Plant Regist 14:288-297. https://doi.org/10.1002/plr2.20042

Barton NH, Etheridge AM, Véber A (2017) The infinitesimal model: Definition, derivation, and implications. Theor Popul Biol 118:50-73. https://doi.org/10.1016/j.tpb.2017.06.001

Baumann U, Bian X, Langridge P (2000) Self-incompatibility in the grasses. Ann Bot 85:203209. https://doi.org/10.1007/978-3-540-68486-2_13

Beavis WD (1994) The power and deceit of QTL experiments: lessons from comparative QTL studies. In: Proceedings of the forty-ninth annual corn and sorghum industry research conference. $\mathrm{p} 266$

Becker R, Wagoner P, Hanners GD, Saunders RM (1991) Compositional, nutritional and functional evaluation of intermediate wheatgrass (Thinopyrum intermedium). J Food Process Preserv 15:63-77. https://doi.org/10.1111/j.1745-4549.1991.tb00154.x

Bernardo R (2014) Genomewide selection when major genes are known. Crop Sci 54:68-75. https://doi.org/10.2135/cropsci2013.05.0315

Bradbury PJ, Zhang Z, Kroon DE, et al (2007) TASSEL: Software for association mapping of complex traits in diverse samples. Bioinformatics 23:2633-2635. https://doi.org/10.1093/bioinformatics/btm308

Browning BL, Browning SR (2016) Genotype imputation with millions of reference samples. Am J Hum Genet 98:116-126. https://doi.org/10.1016/j.ajhg.2015.11.020

Cattani D (2016) Selection of a perennial grain for seed productivity across years: Intermediate wheatgrass as a test species. Can J Plant Sci 524:516-524. https://doi.org/10.1139/cjps- 
Civáň P, Brown TA (2017) A novel mutation conferring the nonbrittle phenotype of cultivated barley. New Phytol 214:468-472. https://doi.org/10.1111/nph.14377

Cornish MA, Hayward MD, Lawrence MJ (1979) Self-incompatibility in ryegrass: I. Genetic control in diploid lolium perenne L. Heredity (Edinb) 43:95-106. https://doi.org/10.1038/hdy.1979.63

Crain J, Bajgain P, Anderson J, et al (2020a) Enhancing crop domestication through genomic selection, a case study of intermediate wheatgrass. Front Plant Sci 11:1-15. https://doi.org/10.3389/fpls.2020.00319

Crain J, DeHaan L, Poland J (2021a) Genomic prediction enables rapid selection of highperforming genets in an intermediate wheatgrass breeding program. Plant Genome. https://doi.org/10.1002/tpg2.20080

Crain J, Haghighattalab A, DeHaan L, Poland JA (2021b) Development of whole-genome prediction models to increase the rate of genetic gain in intermediate wheatgrass (Thinopyrum intermedium) breeding. Plant Genome

Crain J, Larson S, Dorn K, et al (2020b) Sequenced-based paternity analysis to improve breeding and identify self-incompatibility loci in intermediate wheatgrass (Thinopyrum intermedium). Theor Appl Genet 133:3217-3233. https://doi.org/10.1007/s00122-02003666-1

Crews TE, Carton W, Olsson L (2018) Is the future of agriculture perennial? Imperatives and opportunities to reinvent agriculture by shifting from annual monocultures to perennial polycultures. Glob Sustain 1:. https://doi.org/10.1017/sus.2018.11

Culman SW, DuPont ST, Glover JD, et al (2010) Long-term impacts of high-input annual cropping and unfertilized perennial grass production on soil properties and belowground food webs in Kansas, USA. Agric Ecosyst Environ 137:13-24. https://doi.org/10.1016/j.agee.2009.11.008

Culman SW, Snapp SS, Ollenburger M, et al (2013) Soil and water quality rapidly responds to the perennial grain Kernza wheatgrass. Agron J 105:735-744. https://doi.org/10.2134/agronj2012.0273

DeHaan L, Christians M, Crain J, Poland J (2018) Development and evolution of an intermediate wheatgrass domestication program. Sustainability 1-19. https://doi.org/10.3390/su10051499

DeHaan L, Larson S, López-Marqués RL, et al (2020) Roadmap for Accelerated Domestication of an Emerging Perennial Grain Crop. Trends Plant Sci 25:525-537. https://doi.org/10.1016/j.tplants.2020.02.004

DeHaan LR, Ismail BP (2017) Perennial cereals provide ecosystem benefits. Cereal Foods World 62:278-281. https://doi.org/10.1094/CFW-62-6-0278

DeHaan LR, Wang S, Larson SR, et al (2014) Current efforts to develop perennial wheat and domesticate Thinopyrum intermedium as a perennial grain. In: Batello C, Wade L, Cox S, et al. (eds) Perennial Crops for Food Security Proceedings of the FAO Expert Workshop, 2830 Aug. 2013. pp 72-89

Dewey DR (1978) Intermediate wheatgrasses of Iran. Crop Sci 18:43. https://doi.org/10.2135/cropsci1978.0011183x001800010012x

Endelman JB (2011) Ridge regression and other kernels for genomic selection with R package rrBLUP. Plant Genome J 4:250-255. https://doi.org/10.3835/plantgenome2011.08.0024

Endelman JB, Jannink JL (2012) Shrinkage estimation of the realized relationship matrix. 
Genes|Genomes|Genetics 2:1405-1413. https://doi.org/10.1534/g3.112.004259

Fisher RA (1918) The correlation between relatives on the supposition of Mendelian interitance. Trans R Soc Edinburgh 52:399-433

Flint-Garcia SA, Thornsberry JM, Edward IV SB (2003) Structure of linkage disequilibrium in plants. Annu Rev Plant Biol 54:357-374. https://doi.org/10.1146/annurev.arplant.54.031902.134907

Gilmour AR, Gogel BJ, Cullis BR, et al (2015) ASReml User Guide Release 4.1 Functional Specification. VSN International Ltd., Hemel, Hempstead, UK

Glaubitz JCJ, Casstevens TMT, Lu F, et al (2014) TASSEL-GBS: A high capacity genotyping by sequencing analysis pipeline. PLoS One 9:e90346. https://doi.org/10.1371/journal.pone.0090346

Glover JD, Reganold JP, Bell LW, et al (2010) Increased food and ecosystem security via perennial grains. Science (80-. ). 328:1638-1639

Hall D, Hallingbäck HR, Wu HX (2016) Estimation of number and size of QTL effects in forest tree traits. Tree Genet Genomes 12:1-17. https://doi.org/10.1007/s11295-016-1073-0

Hartl DL, Clark AG (1997) Principles of population genetics

Hill WG, Weir BS (1988) Variances and covariances of squared linkage disequilibria in finite populations. Theor Popul Biol 33:54-78. https://doi.org/10.1016/0040-5809(88)90004-4

Isik F, Holland J, Maltecca C (2017) Genetic data analysis for plant and animal breeding. Springer

Jensen KB, Dewey DR, Zhang YFY, Dewey DR (1990) Mode of pollination of perennial species of the Triticeae in relation to genomically defined genera. Can J Plant Sci 70:215-225. https://doi.org/10.4141/cjps90-024

Jensen SE, Charles JR, Muleta K, et al (2020) A sorghum practical haplotype graph facilitates genome-wide imputation and cost-effective genomic prediction. Plant Genome 13:1-15. https://doi.org/10.1002/tpg2.20009

Juliana P, Singh RP, Singh PK, et al (2018) Genome-wide association mapping for resistance to leaf rust, stripe rust and tan spot in wheat reveals potential candidate genes. Theor Appl Genet 131:1405-1422. https://doi.org/10.1007/s00122-018-3086-6

Jungers JM, DeHaan LH, Mulla DJ, et al (2019) Reduced nitrate leaching in a perennial grain crop compared to maize in the Upper Midwest, USA. Agric Ecosyst Environ 272:63-73. https://doi.org/10.1016/j.agee.2018.11.007

K.W. B, S. S (2009) A Guide to QTL Mapping with R/qtl. Springer

Kantarski T, Larson S, Zhang X, et al (2016) Development of the first consensus genetic map of intermediate wheatgrass (Thinopyrum intermedium) using genotyping-by-sequencing. Theor Appl Genet 1-14. https://doi.org/10.1007/s00122-016-2799-7

Keenan K, Mcginnity P, Cross TF, et al (2013) DiveRsity: An R package for the estimation and exploration of population genetics parameters and their associated errors. Methods Ecol Evol 4:782-788. https://doi.org/10.1111/2041-210X.12067

Larson S, DeHaan L, Poland J, et al (2019) Genome mapping of quantitative trait loci (QTL) controlling domestication traits of intermediate wheatgrass (Thinopyrum intermedium). Theor Appl Genet 132:2325-2351. https://doi.org/10.1007/s00122-019-03357-6

Lindberg CL, Hanslin HM, Schubert M, et al (2020) Increased above-ground resource allocation is a likely precursor for independent evolutionary origins of annuality in the Pooideae grass subfamily. New Phytol 228:318-329. https://doi.org/10.1111/nph.16666

Lundqvist A (1954) Studies on self-sterility in rye, Secale cereale. L Hered 40:278-294. 
Lynch M, Walsh B (1998) Genetics and analysis of quantitative traits. Sinauer Sunderland, MA Manzanares C, Barth S, Thorogood D, et al (2016) A gene encoding a DUF247 domain protein cosegregates with the s self-incompatibility locus in perennial ryegrass. Mol Biol Evol 33:870-884. https://doi.org/10.1093/molbev/msv335

Marshall DR, Ellison FW, Mares DJ (1984) Effects of grain shape and size on milling yields in wheat. I. Theoretical analysis based on simple geometric models. Aust J Agric Res 35:619630. https://doi.org/10.1071/AR9840619

Otto SP, Jones CD (2000) Detecting the undetected: Estimating the total number of loci underlying a quantitative trait. Genetics 156:2093-2107

Pavan S, Delvento C, Ricciardi L, et al (2020) Recommendations for choosing the genotyping method and best practices for quality control in crop genome-wide association studies. Front Genet 11:. https://doi.org/10.3389/fgene.2020.00447

Philipp N, Weichert H, Bohra U, et al (2018) Grain number and grain yield distribution along the spike remain stable despite breeding for high yield in winter wheat. PLoS One 13:. https://doi.org/10.1371/journal.pone.0205452

Poland JA, Brown PJ, Sorrells ME, Jannink JL (2012) Development of high-density genetic maps for barley and wheat using a novel two-enzyme genotyping-by-sequencing approach. PLoS One 7:. https://doi.org/10.1371/journal.pone.0032253

Pourkheirandish M, Hensel G, Kilian B, et al (2015) Evolution of the Grain Dispersal System in Barley. Cell 162:527-539. https://doi.org/10.1016/j.cell.2015.07.002

Pugliese JY, Culman SW, Sprunger CD (2019) Harvesting forage of the perennial grain crop Kernza ( Thinopyrum intermedium ) increases root biomass and soil nitrogen cycling. Plant Soil 437:241-254. https://doi.org/10.1007/s11104-019-03974-6

$\mathrm{R}$ Core Team (2020) R: a language and environment for statistical computing

Rafalski A (2002) Applications of single nucleotide polymorphisms in crop genetics. Curr Opin Plant Biol 5:94-100. https://doi.org/10.1016/S1369-5266(02)00240-6

Sehgal D, Mondal S, Crespo-Herrera L, et al (2020) Haplotype-based, genome-wide association study reveals stable genomic regions for grain yield in CIMMYT spring bread wheat. Front Genet 11:1-13. https://doi.org/10.3389/fgene.2020.589490

Smaje C (2015) The strong perennial vision: a critical review. Agroecol Sustain Food Syst 39:471-499. https://doi.org/10.1080/21683565.2015.1007200

Sprunger CD, Culman SW, Robertson GP, Snapp SS (2018) Perennial grain on a Midwest Alfisol shows no sign of early soil carbon gain. Renew Agric Food Syst 33:360-372. https://doi.org/10.1017/S1742170517000138

Storey JD, Tibshirani R (2003) Statistical significance for genomewide studies. 100:6. https://doi.org/10.1073/pnas.91.25.12091

Studer B, Jensen LB, Hentrup S, et al (2008) Genetic characterisation of seed yield and fertility traits in perennial ryegrass (Lolium perenne L.). Theor Appl Genet 117:781-791. https://doi.org/10.1007/s00122-008-0819-y

Tenaillon MI, Sawkins MC, Anderson LK, et al (2001) Patterns of diversity and recombination along chromosome 1 of maize (Zea mays ssp. mays L.). Proc Natl Acad Sci 98:9161-9166. https://doi.org/10.1093/genetics/162.3.1401

Therneau TM (2020) coxme: Mixed Effects Cox Models

Turner S (2017) qqman: Q-Q and Manhattan Plots for GWAS Data

Vico G, Manzoni S, Nkurunziza L, et al (2016) Trade-offs between seed output and life span - a 


\section{$821 \quad$ FIGURES}

822 Fig. 1 genome-wide linkage disequilibrium (LD) for intermediate wheatgrass (Thinopyrum intermedium) for $200 \mathrm{Mb}$ region (a) and $5 \mathrm{Mb}$ region (b). Orange points represent individual marker combinations with a 250-marker sliding window. Average LD has been computed with the Hill and Weir formula (1988) and shown in blue

Fig. 2 Manhattan plots of (a) shattering, (b) brittle rachis, and (c) seed circularity in intermediate wheatgrass (Thinopyrum intermedium) with line indicating 0.05 false discovery rate. Panels $\mathbf{d}, \mathbf{e}$ and $\mathbf{f}$ show quantile-quantile (QQ) plots for $\mathrm{p}$ values under the null hypothesis (no association) and observed $\mathrm{p}$ values for brittle rachis (d), shattering (e), and seed circularity (f), respectively

Fig. 3 Distribution of phenotypic values for shattering and brittle rachis (a and $\mathbf{b}$ respectively), where lower values are preferred, at the marker loci SS04_341952545 and SJ03_115931563 in intermediate wheatgrass (Thinopyrum intermedium). Panels $\mathbf{c}$ and $\mathbf{d}$ displays the allele (line plots) and genotype (points, $\mathrm{H}$ is heterozygote) frequency change for the shattering marker in The Land Institute (TLI) Cycle 6 to 9 breeding populations, population differentiation expressed with $F_{S T}$ between TLI Cycle 6 and TLI Cycle 9

\section{TABLES}

Table 1 Significant quantitative trait loci (QTL) associations in The Land Institute intermediate wheatgrass (Thinopyrum intermedium) breeding program for priority traits

Table 2 Number of estimated quantitative trait loci (QTL) for phenotypic traits in intermediate wheatgrass, and the estimated population size to needed to detect QTLs explaining 50\% of the genotypic variance

Table 3 Fixation index, $F_{S T}$, values for all single nucleotide polymorphisms (SNPs) in The Land Institute intermediate wheatgrass breeding population cycles 6 and 9

Table 4 Biallelic reference allele frequency for four breeding cycles in The Land Institute breeding program that had Fixation index, $F_{S T}$, greater than 0.15 
855 Supporting Information Table S1 Descriptive statistics, including total number and number of genets by cycle, of the best linear 856 unbiased predictors of 34 traits measured in The Land Institute intermediate wheatgrass breeding program cycles 6-9 during 2016$857 \quad 2020$

858

\begin{tabular}{|c|c|c|c|c|c|c|c|c|c|}
\hline Trait & C6 n & C7 n & C8 n & C9 n & Total n & Min. & Max. & Mean & STD \\
\hline Brittle Rachis & 0 & 1186 & 947 & 955 & 3088 & 0.49 & 1.63 & 0.99 & 0.17 \\
\hline Seed Image Circularity & 1013 & 1151 & 940 & 926 & 4030 & 0.37 & 0.55 & 0.45 & 0.02 \\
\hline Spike Emergence $(\mathrm{cm})$ & 0 & 1180 & 0 & 0 & 1180 & 1.8 & 36.69 & 19.79 & 6.13 \\
\hline Seed Length (mm) & 1013 & 1183 & 976 & 926 & 4098 & 5.07 & 8.13 & 6.68 & 0.41 \\
\hline Seed Width (mm) & 1013 & 1183 & 976 & 926 & 4098 & 1.29 & 1.8 & 1.55 & 0.07 \\
\hline Flag Leaf Length $(\mathrm{cm})$ & 982 & 0 & 0 & 0 & 982 & 20.18 & 36.03 & 27.87 & 2.23 \\
\hline Flag Leaf Width (mm) & 982 & 0 & 0 & 0 & 982 & 8.83 & 23.79 & 15.75 & 1.91 \\
\hline Flag Leaf Height (cm) & 924 & 0 & 0 & 0 & 924 & 37.51 & 78.12 & 63.86 & 5.71 \\
\hline Number of Florets per Spike & 1019 & 1176 & 873 & 0 & 3068 & 123.17 & 230.38 & 174.13 & 14.49 \\
\hline Number of Florets per Spikelet & 1019 & 1176 & 873 & 0 & 3068 & 6.41 & 9.79 & 7.66 & 0.44 \\
\hline Spike Emergence \% & 918 & 1130 & 0 & 0 & 2048 & 0.05 & 1.31 & 0.64 & 0.18 \\
\hline Lodging & 0 & 1182 & 938 & 0 & 2120 & 2.42 & 8.89 & 5.98 & 1.05 \\
\hline Free Threshing & 1014 & 1184 & 979 & 937 & 4114 & 2.3 & 98.37 & 57.17 & 17.1 \\
\hline Peduncle Width (mm) & 0 & 1150 & 0 & 0 & 1150 & 7.71 & 11.99 & 9.9 & 0.69 \\
\hline Floret Site Utilization & 1012 & 1173 & 864 & 0 & 3049 & 0.12 & 0.39 & 0.22 & 0.03 \\
\hline Plant Height (cm) & 1020 & 1191 & 992 & 954 & 4157 & 82.87 & 136.54 & 111.03 & 5.92 \\
\hline Seed Area $(\mathrm{mm} 2)$ & 1013 & 1183 & 976 & 926 & 4098 & 5.39 & 10.59 & 8.08 & 0.68 \\
\hline Seed Density & 1013 & 1183 & 976 & 926 & 4098 & 0.97 & 1.67 & 1.31 & 0.08 \\
\hline Seeds per Spike & 1016 & 1186 & 980 & 958 & 4140 & 10.7 & 62.24 & 38.21 & 6.8 \\
\hline Seed Mass (mg) & 1013 & 1183 & 977 & 937 & 4110 & 5.89 & 13.34 & 9.46 & 1.08 \\
\hline Seed Perimeter (mm) & 1013 & 0 & 0 & 0 & 1013 & 11.2 & 17.55 & 14.73 & 0.95 \\
\hline Shattering & 1019 & 1188 & 981 & 948 & 4136 & 0.17 & 3.79 & 2.13 & 0.57 \\
\hline Spikelet Density & 1017 & 0 & 0 & 0 & 1017 & 0.52 & 1.06 & 0.72 & 0.06 \\
\hline Spike Dry Weight (g) & 0 & 1167 & 955 & 959 & 3081 & 0.83 & 1.75 & 1.31 & 0.13 \\
\hline Spiklets per Spike & 1019 & 1176 & 873 & 0 & 3068 & 18.02 & 27.36 & 22.69 & 1.13 \\
\hline Spike Harvest Index & 0 & 1156 & 955 & 958 & 3069 & 0.11 & 0.46 & 0.3 & 0.05 \\
\hline Spike Length (cm) & 1017 & 1141 & 0 & 0 & 2158 & 22.59 & 45.88 & 34.78 & 2.86 \\
\hline Spike Yield (g) & 1019 & 1188 & 981 & 958 & 4146 & 0.14 & 0.58 & 0.36 & 0.06 \\
\hline Stem Angle & 1022 & 1179 & 0 & 0 & 2201 & 19.26 & 82.33 & 53.86 & 9.99 \\
\hline Stem Strength Bottom & 914 & 0 & 0 & 0 & 914 & 1214.48 & 3424.35 & 2181.99 & 344.09 \\
\hline
\end{tabular}


Stem Diameter (mm)

Stem Strength Middle

Stem Strength Top

Maturity

859

$\begin{array}{rrrrrrrrr}946 & 0 & 0 & 0 & 946 & 2.24 & 3.89 & 3.01 & 0.21 \\ 915 & 1174 & 0 & 0 & 2089 & 747.15 & 1910.92 & 1197.3 & 166.77 \\ 915 & 0 & 0 & 0 & 915 & 288.65 & 615.32 & 418.66 & 53.05 \\ 1017 & 1189 & 944 & 953 & 4103 & 52.21 & 69.9 & 63.14 & 1.48\end{array}$


860

\begin{tabular}{|c|c|c|c|c|c|c|c|c|c|c|c|c|c|c|c|c|c|}
\hline \multirow{2}{*}{ Trait } & \multicolumn{17}{|c|}{ Chromosome } \\
\hline & $\mathbf{J 2}$ & J3 & J4 & J5 & $J 6$ & J7 & S1 & S2 & S3 & S4 & S5 & S7 & V1 & V2 & V3 & V5 & v6 \\
\hline Brittle rachis & & $C, 7,8,9$ & & & & & & & $\mathrm{C}, 7,9$ & & $C, 7$ & 9 & 7 & & & 7 & \\
\hline Flag leaf length & & 6 & & & & & & & & & & & & & & & \\
\hline Flag leaf width & & & & & & & & & & & & & 6 & & & 6 & \\
\hline Floret site utilization & & & & & & & & & & & $\mathrm{C}, 7$ & & & & & & \\
\hline Free threshing & & & & & & & & & & & & & & $\mathrm{C}, 9$ & & & \\
\hline Maturity & 7 & & & & 6 & & & & & & & & & & & & \\
\hline Number of florets per spike & & & & C & & & & & & & & & & & C & & \\
\hline Number of florets per spikelet & C & & & C & & & & & & & & & & & & & \\
\hline Peduncle width & $\mathrm{C}, 7$ & & & & & & & & & & & & & & & & \\
\hline Plant height & & & & & 7,8 & & & & & & & & & & & & \\
\hline Seed area & & & & & & 6 & & & & & & 8 & & & & & \\
\hline Seed density & & & & & & & C & & & & & C & & & & & \\
\hline Seed image circularity & & c & & & & & $\mathrm{C}, 7,8$ & & & $\mathrm{C}, 6$ & & $C, 6,7,8$ & $C, 6,7$ & c & & $\mathrm{C}, 6,7$ & \\
\hline Seed length & & & & & & & & & & & & 7 & c & & & & c \\
\hline Seed width & C & & $\mathrm{C}, 7$ & & & 9 & & & & & & & & $\mathrm{C}, 6$ & & & \\
\hline Shattering & C & & & & & & 7 & $C, 7,8,9$ & 7 & $C, 7,8,9$ & $C, 7,8$ & & & 7 & & & \\
\hline Spike emergence & $\mathrm{C}, 7$ & & & & & & & & & & & & & & & & \\
\hline Spike emergence $\%$ & $\mathrm{C}$ & & & & & & & & & & & & & & & & \\
\hline Spike length & & & & & & & & & & & C & & 7 & & & & \\
\hline Spikelet density & & & & & & & & & 6 & & & & & & 6 & & \\
\hline Spikelets per spike & & & & & & & & c & & & & 6 & & & & & \\
\hline Stem strength bottom & & & & & & & & & 6 & & & & & & & & \\
\hline Stem diameter & & & & & & $\mathrm{C}, 6$ & & & & & & & & & & & \\
\hline Stem strength middle & & & & & & & & & 6 & & & & & & & & \\
\hline
\end{tabular}

QTL\#, number of QTL; Associated markers, number of markers associated with each QTL; Chr, chromosome; n, number of individuals observed; $F_{S T}$ fixation index between The Land Institute (TLI) Cycle 6 and TLI Cycle 9; PVE, percent variance explained; Ref/Alt reference and alternate allele respectively; MAF

Supporting Information Table S3 Chromosome location of genome-wide associations by trait for combined analysis (C) and individual cycle combinations (6-9) for The Land Institute intermediate wheatgrass breeding program 


\section{Supplementary Files}

This is a list of supplementary files associated with this preprint. Click to download.

- SupportingFigureS1.png

- SupportingFigureS2.png

- SupportingFigureS3.png

- SupportingFigureS4.png

- SupportingInformationTable2.xIsx 